\title{
Evaluating the Quality of Health services provided to the population of The Arab Republic of Egypt
}

\author{
Mona Saeed Mohamed \\ Cairo University \\ Institute of Statistical Studies and Research \\ Montysharawy36@gmail.com \\ Recived : $12 \backslash 3 \backslash 2018$ \\ Revised : 9\4\2018 \\ Accepted : 17\4\2018 \\ Available online : $17 / 5 / 2018$ \\ DOI: $10.29304 / j q c m .2018 .10 .2 .388$
}

\begin{abstract}
Egypt is the most populous country in the Middle East and it was ranked 111 among the ranks of 188 countries in the human world report of 2016 so it was necessary to adopt effective programs for human development especially that direct to health, because health has become a standard of well-being in developed countries. Among the population targets in Egypt is raising the health properties of citizens and provide a good health program able to protect them from the risk of diseases. One of these efforts is the establishment of the general Authority for social health insurance as a health experiments. Its health services cover more than $59 \%$ of the total population in 2017 which means that it included more than half of the population. It becomes the most important health establishment in the country which protects people from the risk of diseases. One of the advantages of this experiments, it's not completely free and it's not completely high cost.
\end{abstract}

Key words: Health Insurance - Health Care - World Health Indicators - Health Programs Disease. 


\section{Preface:}

Human health is a grant from God Almighty, which must be preserved and protected from disease and its causes, so that the individual remains strong and able to perform his religious and mundane duties, which Allah created for him.

To maintain health one must have a clear background on the health culture, so that it does not flounder in dealing with its health, body and diseases, which does not resort to traditional recipes, and not based on scientific and medical, because they are counterproductive, Comprehensive health coverage directly affects the health of the individual, as health services enable him to increase his productivity and

contribute actively to the well-being of his family and society. These services also ensure that children can go to school and learn. Comprehensive health coverage is a critical component of sustainable development, poverty reduction and an essential component of efforts to reduce inequities in society.

The research is divided into eight sections as follows:

1- Problem of study

2 - Questions of the study

3 - Study hypotheses

4- Previous studies.

5. Contextual framework.

6. Objectives of the study.

7. Data and methodology.

8. Conclusion and recommendations.

\section{1- Problem of study:}

One of the three components of the population problem in Egypt is the low population characteristics. At the top of these low characteristics is the low level of health of citizens, which has abnormal repercussions in the spread of diseases such as ( $\mathrm{C}$ virus and kidney failure and ............... . the main locomotive to raise the level of health in Egypt is the General Authority for Health Insurance(HIO) because its medical services cover more than half of the population 59\% in 2017 If these services upgraded to the required level, it will lead to a positive and significant change in the health level of citizens in Egypt and therefore It was necessary to evaluate the performance of the medical activities provided by the General Authority for Health Insurance(HIO) In order to determine how to improve their performance in the case of negative indicators or to maintain their role as in the case of proving the quality of health care provided to the beneficiaries and to examine the shortcomings of the health services provided and how to address them and determine the geographical locations that have not been served healthily Enough.

\section{2- Study Questions:}

1. How effective are the health services provided to beneficiaries in the public health of the State?

2. Are the physical, human and therapeutic resources available to the HIO sufficient to provide medical services to the beneficiaries?

3. Are the funds allocated to the health care provided by HIO to the beneficiaries sufficient to provide the service in a suitable manner?

4- Is the mortality rate in health insurance hospitals low?

5-How much will beneficiaries be in 2025 ? 


\section{3 - Study hypotheses:}

1- Medical services provided to all geographical locations in the Arab Republic of Egypt.

2 - There is a lack of performance of medical service providers.

3. There is a difficulty in reaching specific medical standards according to the World Health Organization.

4 - There is a negative impact of some medical activities provided to each other.

\section{Previous studies:}

Several studies dealt with the extent of the health insurance umbrella. These studies concluded that social health insurance should be included for all social groups. Other studies also examined the obstacles and problems of social health insurance. These studies concluded that health insurance still faces technical, administrative and financial problems. The importance of performance improvement in hospitals and solving the problems facing it and the development of a plan and time period for this development. There are other studies concerned with comparing the systems applied in social health insurance to some countries. It concluded that to develop the health sector in the country, the health sector should be organized, the role of the service providers should be reviewed and the comprehensive coverage and distribution justice should be implemented. Improve quality and suitability with demand by respecting health controls and standards.
There are studies to assess the current situation of social health insurance and concluded that the health insurance status is still continuing as it is in the forefront and bears the burden of the high cost of incurable diseases.

\section{Contextual framework:}

The theoretical framework is important because it explains a large number of variables affecting the quality and efficiency of the medical service provided to beneficiaries. These variables affect and are directly and indirectly affected by each other.

1- Medical service outlets.

2. Population groups receiving medical service.

3- Type of medical service provided.

4 - Method of funding the medical service provided.

5. Cost of medical services.

6. Time required for medical service.

7. The material and human resources necessary to provide the service. 


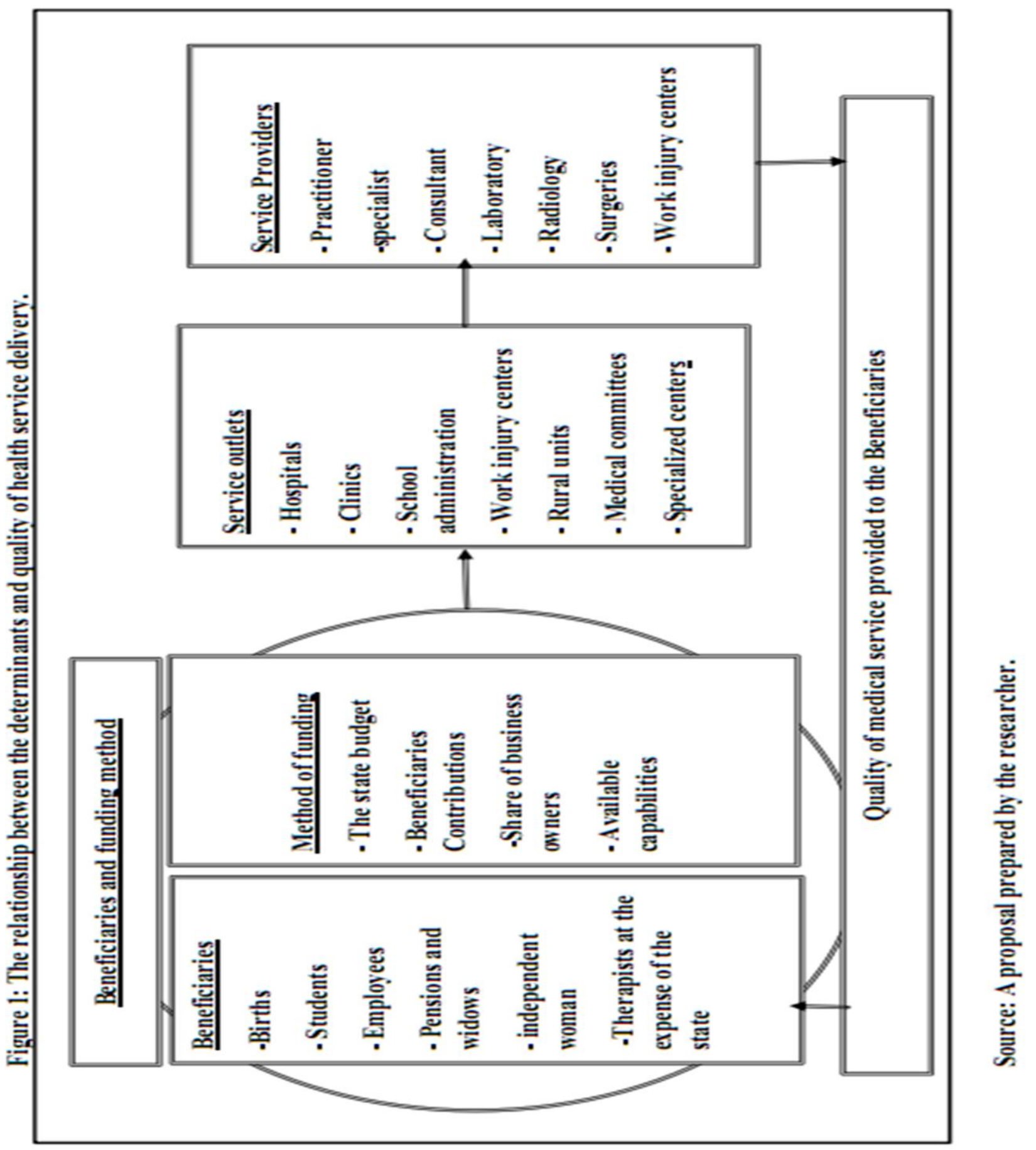




\section{6- Objectives of the study}

\section{A._Genereral Objectective:}

Conducting an evaluation study of the health care activities provided by HIO for the inhabitants of the Arab Republic of Egypt according to international and local indicators to ensure the provision of a distinguished health service to all health insurance associates in the republic without distinction.

\section{B. Sulb-objejectiveses:}

1- Research the shortcomings of the health services provided.

2. Identify geographical locations that have not been sufficiently served.

\section{7- Data and methodology}

Performance evaluation criteria were used for the medical activities provided in accordance with Egyptian law and compared with the WHO standards, including the following:

- Performance evaluation criteria for medical activities provided.

\section{- Prediction of time series with}

\section{ARIMA model.}

First Evaluation of medical activities provided to the population in the

\section{Arab Republic of Egypt:}

Here, the population will be divided into a number of segments: students / births / workers in the public, private sectors and government / Independent women / work injuries.

The medical services should be evaluated for each of the previous segments as follows: Service of the practitioner / Specialist / beds service in hospitals.

\section{School students:}

1- Percentage of vaccinations given to school students and kindergartens ranges between $41 \%$ and $100 \%$ for all students in all governorates of the Republic according to the data of the report of HIO, 2012.

2 - Criteria to evaluate the quality of the performance of medical service provided to school students according to human and physical potential:

* - Practitioner service: Cairo governorate is one of the most urban governorates that need to increase the number of practicing doctors by 307 practicing doctors because the lack of the number of practicing doctors will lead to a terrible accumulation of clinics in the governorate, which needs to display 15 cases on the doctor within one minute which Indicates the poor quality of medical service provided to students in that governorate, which is considered the capital of Egypt. In order to achieve the ideal standard that Egypt seeks for its students and to improve the quality of the medical service provided to them, the number of practicing physicians should increase to 848 doctors to participate in the number of students who attend it during the year 2500 students, 8 students per day and one student every hour. In the order of North West Delta (Alexandria and Matrouh) where the quality of medical service is not good because it is impossible to present 9 cases to the practitioner within one minute. Requiring an increase in the number of practicing physicians to 500 . 


\section{* Births:}

1 - availability of a reception department working 24 hours found no problem in the availability of reception departments in all governorates except Ismailia, South Upper Egypt and Luxor, due to the lack of the establishment of hospitals in those governorates, but there are only clinics and medical complexes provide treatment services for newborns and in the case of One of the newborns is exposed to any emergency condition. The medical service is provided by either the third party contracting with the Commission or through the transfer to the nearest hospital in the neighboring governorate and closest to their place of residence.

\section{* Workers in the private, public and}

\section{government sectors:}

1 - Evaluation of medical services provided to employees in the private, public and government sector According to the available physical resources of the numbers of comprehensive clinics there is a convergence between the standard of the Ministry of Health and what is on the ground as the case in the North West Delta, Port Said and Minya There is a large disparity To be taken into clinics are provided to serve the beneficiaries in the following governorates of Gharbya , Giza and Cairo finally there are some governorates where there is no problem in serving beneficiaries of the workers in accordance with Law 32 and Law 79, where there is an abundance of clinics The governorates of Dakahlia, Beni Suef, Kafr El-Sheikh, Beheira, Damietta, Suez, Fayoum, and Sohag .

\section{* Pensions and widows:}

* - Practitioner service: There is an abundance of practitioners in all governorates and some rural and upper governorates. Therefore, we found that the most governorates that need to increase the number of practitioners are Qaliubiya, Gharbia, Dakahlia, Beheira, Menia, Menoufia, Fayoum, Ismailia and Beni Suef. Respectively, in order to provide the service in full and in a short time without long waiting in the restroom until the presentation to the practicing doctor.

* Specialist service: There is an abundance of numbers of specialists in the following specialties (internal / chest / heart / general surgery / nose and ear / brain and neurological / emphysema / skin and genital) and there is no problem in the numbers on these disciplines.

\section{* independent women:}

* - Practitioner service: we found that there is no problem in the availability of doctors practicing in all the urban governorates, and rural governorates where the service of the best practice only in three branches are respectively as follows: Minya / ELbheira / Dakahlia.

\section{* Beneficiaries of work injuries:}

* Practitioner service: There is a great shortage in the number of general practitioner compared to the number of participants with work injuries and the most governorates that need to increase the number of doctors is Cairo, followed by North Upper Egypt and Northwest Delta. Doctors to the ideal standard of 2000 cases per year, bringing the total number of practicing doctors to 7599 doctors distributed in all governorates.

* Specialist service: There is an abundance of specialists and there is no shortage, where there is one or two cases in the year for the specialist, which indicates that there is no problem in the time required to provide service for that category. 


\section{Second Time series prediction with ARIMA model:}

\section{Figure 2 Number of patients:}

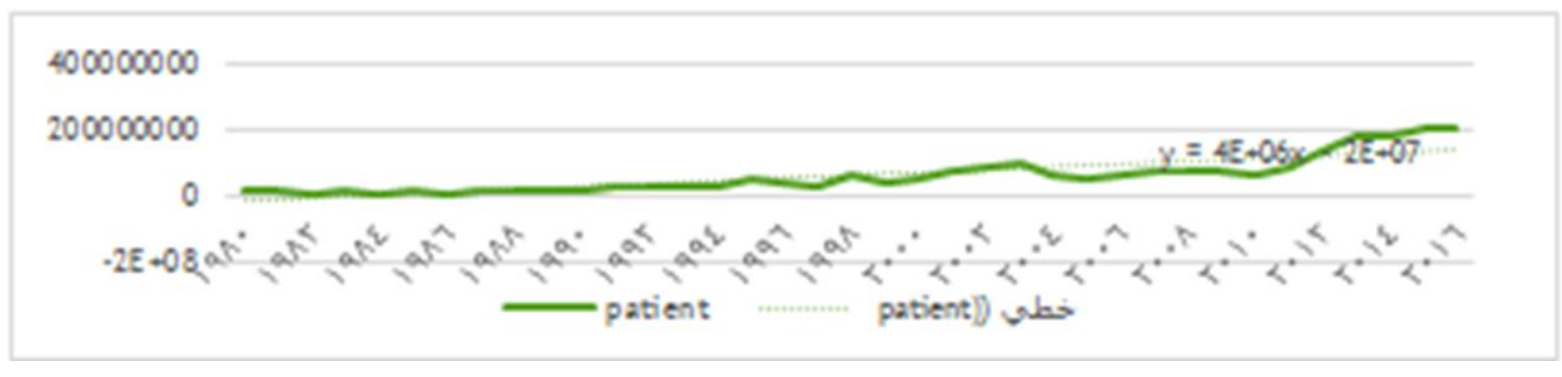

The previous figure shows that the time series has a general direction of the increase and suffers from the problem of unit root, therefore, it is difficult to rely on the previous series to obtain accurate measurements. Unit root was tested in the expanded Dicky- Fuller method.

Table 2: Number of expected patients during the period from 2017 to 2025.

\begin{tabular}{|c|c|c|c|}
\hline years & Max & expected & Min \\
\hline 2017 & 2.70 & 2.42 & 1.57 \\
\hline 2018 & 3.07 & 2.67 & 1.51 \\
\hline 2019 & 3.48 & 2.95 & 1.44 \\
\hline 2020 & 3.92 & 3.26 & 1.36 \\
\hline 2021 & 4.41 & 3.61 & 1.27 \\
\hline 2022 & 4.94 & 3.99 & 1.15 \\
\hline 2023 & 5.52 & 4.42 & 1.02 \\
\hline 2024 & 6.17 & 4.90 & 0.85 \\
\hline 2025 & 6.88 & 5.43 & 0.66 \\
\hline
\end{tabular}

Source: According to researcher.
Since the unit root test is not significant at the $10 \%$ level of -1.611 , we reject the alternative hypothesis and accept the null hypothesis that the series is not static at $10 \%$, and it is possible to obtain a stable series by the first difference.

$$
\mathrm{Y}_{\mathrm{t}}=\log \left(\mathrm{y}_{\mathrm{t}-1}\right)+\operatorname{ar}(1)+\mathrm{ma}(1)+\mathrm{e}_{\mathrm{t}}
$$

The value of R_Square of 0.92 and the value of Durbin Watson $=2.06$ indicates the quality of the prediction model and the predictability value of the policy stability until 2025 is as follows: 
Figure 3: The minimum, highest, and expected number of patients.

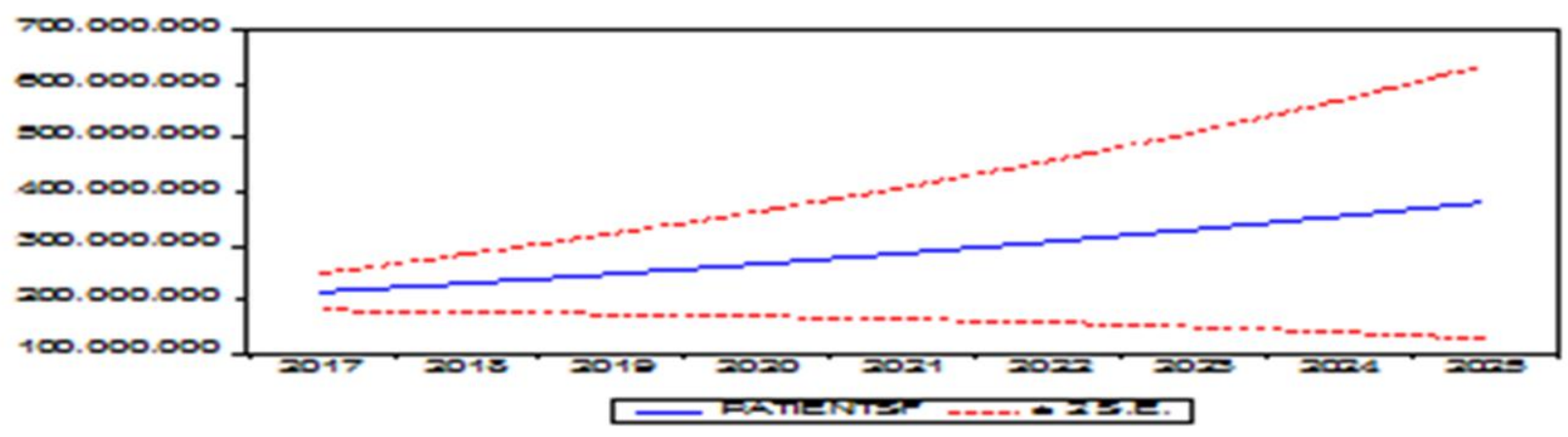

\section{A - Examination of the coefficients of the function of autocorrelation and partial correlation}

The coefficients of the autocorrelation and the partial correlations were observed within $95 \%$ confidence intervals. This indicates the suitability of the model to analyze the series data.

\section{B) The L Jung-Box $O$ test}

We found that the test was 0.36 , indicating the randomness of the residual.

As for the analysis of the residual, we found that the quality criteria for the model and according to EVIEWS program as follows:

\section{*- SERIAL CORRELATION:}

We accepted the null hypothesis and the absence of auto-correlation of the first degree in the residual, where the probability is 0.20

\section{*-Heteroskedasticity:}

Here we will use the Arch effect method. We accept the null hypothesis because the probability is 0.72.variance is constant and is achieved when the probability is greater than 0.05 .

\section{*-Normality Test:}

We found that the residuals follow the normal distribution of the probability of 0.1342 .

\section{*- Checking model's residuals:}

By examining the auto-correlative function of the residuals, it was found that it was interrupted after the first time unit and that the partial auto-correlation function decreased gradually. This results in the errors being followed by random changes. The first difference of the stacks obtained from the model follows the process of moving averages with parameter $\theta=1$ Of the first level $p=-0.5$ Thus, the following tests are performed:

Test $1(\Theta=1 \quad$ VS $\quad \Theta \neq 1)$

Therefore, we accept the null hypothesis that the value of the parameter $\Theta$ is not significantly different from the one, the errors in the model follow purely random changes.

Test $2(p=-0.5$ VS $p \neq-0.5)$

For the second test of the auto-correlation coefficient, we accept the null hypothesis that $p$ is significantly different from -0.5 and this confirms the suitability of the model.

\section{*- Random forms}

In order to enhance trust, the residuals were drawn against time, and from this we found the dispersion of the planks around the semi-stable medium. As we observe when drawing the errors against the estimated value, there is no correlation between the residuals and the estimated values. 


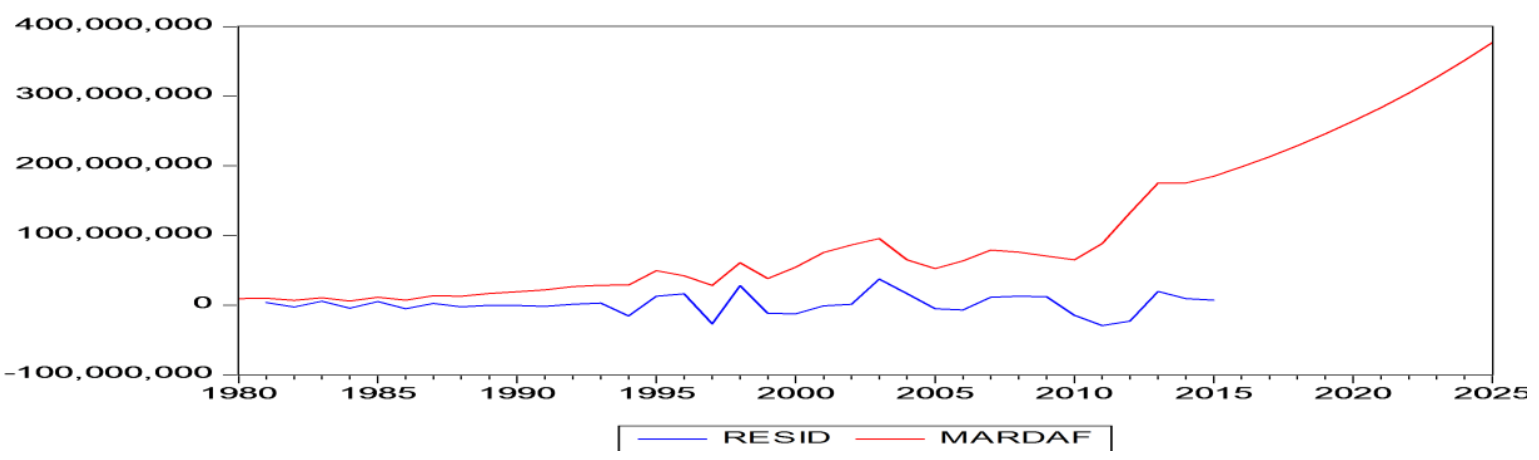

Figure 4: The correlation between the residuals and the estimated values

\section{Model quality standards:}

It is clear from the previous model that its quality standards are as follows:

Table 3: Model quality standards

\begin{tabular}{|l|l|}
\hline \multicolumn{1}{|c|}{ Measure } & Value \\
\hline Theil inequality coefficient & 0.115059 \\
\hline Mean Abs .Percent Error & 27.07841 \\
\hline Mean Absolute Error & 13409587 \\
\hline Root Mean squared Error & 19293877 \\
\hline \multicolumn{2}{|l}{ Source: According to researcher. }
\end{tabular}

\section{*- predictive power of the model:}

There is no doubt that the prediction is an important and prominent role in the decisionmaking process because by predicting the numbers of health service providers predict their needs of possibilities Such as the number of doctors, nurses, pharmacists, service workers, technicians and other health professionals

Table 4: Forecasting the physical and human potential of 2025 according to the standards of Egyptian law.

\begin{tabular}{|c|c|c|c|l|}
\hline Max & Expected & Min & Egypt standards & \multicolumn{1}{|c|}{ Statement } \\
\hline 2752000 & 2172000 & 264000 & $1000 / 4$ & beneficiary /Number of beds \\
\hline 17200 & 13575 & 1650 & $40000 / 1$ & beneficiaries /Number of clinics \\
\hline 68800 & 54300 & 6600 & $10000 / 1$ & Beneficiary /Dental Specialist \\
\hline 2752000 & 36200 & 264000 & $1000 / 4$ & Beneficiary /Nurse \\
\hline 45867 & 36200 & 4400 & $15000 / 1$ & Beneficiary/Internal Specialist \\
\hline 34400 & 27150 & 3300 & $20000 / 1$ & Beneficiary/Specialist in General Surgery \\
\hline 22933 & 18100 & 2200 & $30000 / 1$ & beneficiary /Specialist of nose and ear \\
\hline 17200 & 13575 & 1650 & $40000 / 1$ & Beneficiary /Specialist Chest \\
\hline 2752000 & 2172000 & 264000 & $1000 / 4$ & Beneficiary /Service Agent \\
\hline
\end{tabular}

\section{Source: According to researcher.}


Table 5: Predicting the physical and human potential of 2025 according to WHO standards:

\begin{tabular}{|c|c|c|c|l|}
\hline Max & Expected & Min & WHO standards & Statement \\
\hline 10320000 & 8145000 & 990000 & $1000 / 15$ & beneficiary /Number of beds \\
\hline 68800 & 54300 & 6600 & $10000 / 1$ & beneficiaries /Number of clinics \\
\hline 1376000 & 1086000 & 132000 & $1000 / 2$ & Beneficiary /Nurse \\
\hline 344000 & 271500 & 33000 & $2000 / 1$ & Beneficiary /Pharmacist \\
\hline 1376000 & 1086000 & 132000 & $500 / 1$ & Beneficiary /Service Agent \\
\hline
\end{tabular}

\section{Source: According to researcher.}

\section{8- Conclusion and Recommendations}

This section presents the main findings of the study:

1- There are governorates that have not been served as well as Luxor governorate.

2- not to include health insurance for all segments of society, and this leads to the exposure of this category of disadvantaged health insurance to the risk of destitution and disease because of the costs of treatment and increases the risk of development of the disease because of its inability to pay the cost of treatment, which may deprive treatment and may lead to Worsening disease or death.

3- There is a significant decrease in the physical, human and therapeutic potential available in HIO in the Arab Republic of Egypt, which affects the medical service provided to the beneficiaries.

4- The proportion of medical examinations and vaccinations given to school students and kindergartens exceeds $90 \%$ in most governorates.

\section{8- Recommendations}

Based on results, the study recommends the following:

1 - Establishment of a hospital in Luxor to accommodate the sick cases in that governorate and to reduce the cases transferred to other governorate to receive the required health service.

2 - We must raise the level of medical service provided to citizens in order to benefit the desired development in the State.

3. Re-distribution of health services according to population needs.

4. Social health insurance must play an active role in raising the level of job satisfaction and social security among individuals.

5 - Inclusion of health insurance for all segments of society, including housewives and irregular labor, because of their inability to afford the financial burdens related to the costs of treatment.

6 - We need to follow up the technical performance of medical activities in hospitals through specific quality programs in advance, which contributes to solving the problems that occur on the surface and the development of a time plan for this program. 


\section{References:}

[1]-Abbasi, Abdul-Hamid, 2005 / Comparison of Neural Networks and Traditional Statistical Methods to Predict Traffic Deaths in Kuwait Egyptian Journal of Population and Family Planning - Issue 1 - June - Vo 1.

[2]-Ashoury, Hadi - 1996 - / Financing of health services in the Republic of Tunisia Journal of Social Health Insurance - Issue Thirty-eighth.

[3]-Banop, Samir - 1997 / the world's dominant systems in the financing and regulation of health services - Journal of Social Health Insurance - Issue Thirty-eighth.

[4]-Central Agency for Public Mobilization and Statistics (Egyptian Household Expenditure on Health Services, 2012-2013). [5]-Demographic health survey - 2014 Ministry of Health and Zanati.

[6]-Hawari, Osama Mohamed - 2006 / Health care systems applied in the Arab Republic of Egypt and the site of health insurance, including - Social Insurance Journal - the fourth issue and the seventy.

[7]-Hawari, Osama Mohammed - 2014 / health insurance in the fiftieth year - Journal of social health insurance - the number one hundred and four.

[8]-Human Development Report Egypt - 2014, Institute of National Planning, Cairo.

[9]-Muhairi, Nabil - 1995 / Health Care Insurance in Korea - Research Paper - Social Health Insurance Magazine - Issue Nineteen. [10]-Radwan, Refaat - 1995 / Trends of health insurance in Egypt over the next ten years Journal of Social Health Insurance - Thirty one.
[11]-Radwan, Rifaat - 1993 / The beginning of the truth to build a generation capable of production - Journal of Social Health Insurance - Issue Twenty-third.

[12]-Radwan, Rifaat - 1996 / The Future of Health Insurance in Egypt and the Integral Role of Health Institutions with the Introduction of the Twenty-first Century Journal of Social Health Insurance - Issue No. 32.

[13]-Rizk, Alfons Shehata - 1992 / Health Insurance and Management - Research Paper Journal of Social Health Insurance - Number Twenty.

[14]-Rizk, Alfons Shehata - 1994 / Health Insurance and Distribution Justice - Journal of Social Health Insurance - Issue Twenty-fifth. [15]-Saleh, Saleh Mahmoud - 2006 / Medical review in the management of hospitals Journal of social health insurance - the second issue and the seventy.

[16]-Shehata, Mohamed - 1986 / Problems of the application of social health insurance in Egypt - Journal of social health insurance - the eleventh issue.

[17]-Tahimer, Abdel-Azim 2007 / Medical insurance for students and births - Journal of social health insurance - the number eightyseventh.

[18]-Zaki, Hassan Abdel Fattah - 2007 / towards a proposed new law for health insurance - Journal of Social Health Insurance - Issue No78. 
تقييم جودة الخدمات الصحية المقدمة للسكان بجمهورية مصر العربية

$$
\begin{aligned}
& \text { منى سعيد محمد محمود شعراوى } \\
& \text { جامعة القاهرة } \\
& \text { معهد الاراسات و البحوث الإحصائية } \\
& \text { قسم الإحصاء الحيوي و السكاني }
\end{aligned}
$$

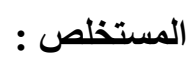

فى هذا البحث تم دراسة مدى جودة الخدمات الصحية المقدمة للسكان بجمهورية مصر العربية عام 2017 من قبل الهيئة العامة للتامين الصحى الإجتماعى بالإضافة الى استخدام نموذج ARIMA فى التنبؤ بإحتياجات السكان من

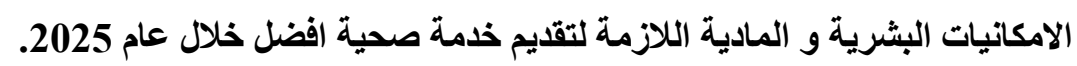

